\title{
Preface to the Special Issue on MAF11 Conference Proceedings
}

\author{
Janos Matko
}

Published online: 15 June 2011

(C) Springer Science+Business Media, LLC 2011

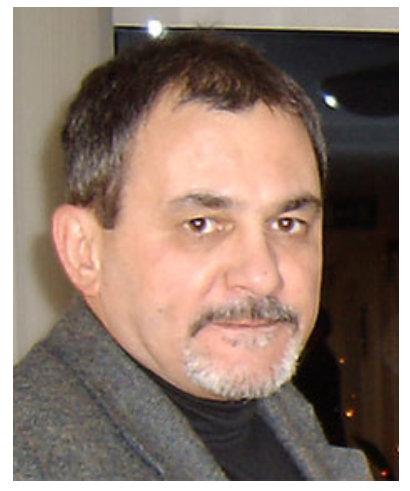

The Journal of Fluorescence is tradititonally publishing, since a long time, a significant fraction of works presented at the respective International Conferences on Methods and Applications of Fluorescence, the MAF series. This issue contains full papers of contributions to MAF11 Conference held in Budapest, Hungary, between September 6-9, 2009.

The MAF Conferences usually cover many aspects of fluorescence theory, applications and developments, including all kinds of fluorescence spectroscopy, fluorescence imaging and fluorescent probes. This time this area was further extended towards complex, fluorescence-based high throughput technologies, microchips and arrays, as well. The works included in this issue include various reasearch topics, among others, design and development of new fluorescent probes; new technologies to improve fluorescence detection in chemistry and biology; frequency- and time-domain fluorescence spectroscopy and imaging; solvent relaxation, protein structural and protein-protein interaction studies; nanoparticles and their applications in bio-medical research; fluorescent sensors, microchips, microarrays, etc. Fluorescent correlation spectroscopy and other special techniques assisting biomedical research will also be involved, such as various biohysical and bioanalytical approaches, all demonstrating the high level of interdisciplinarity of this Conference series.

MAF-11 was attended by closely 300 participants, such as the recent meetings held in Graz (2007), Lisbon (2005) or Prague (2003). The success of the Budapest meeting further confirms the viability and usefulness of this conference series (since 1989), which became a traditionally leading event of scientists working on understanding fluorescence principles or applying fluorescence in a variety of scientific fields, such as chemistry, physics, biology, medicine or industry. This MAF series traditionally results in new contacts between the participants and interdisciplinary communications realized often in new joint research. We believe that this tradition will continue in the future, as well. The next MAF Conference will be held in Strasbourg, France, in 2011. For further information see: htttp://www.maf-sip-com

Budapest, October, 2009.

Janos Matko

Conference Chairman

\footnotetext{
J. Matko ( $\triangle)$

Institute of Biology, Department of Immunology,

Eotvos Lorand University,

1117 Budapest, Hungary

e-mail: matko@elte.hu

URL: http//:immunologia.elte.hu
} 